\title{
Spatiotemporal Coding of Individual Chemicals by the Gustatory System
}

\author{
(DSam Reiter, ${ }^{1,2}$ Chelsey Campillo Rodriguez, ${ }^{1}$-Kui Sun, ${ }^{1}$ and ${ }^{\circledR}$ Mark Stopfer ${ }^{1}$ \\ ${ }^{1}$ National Institute of Child Health and Human Development, National Institutes of Health, Bethesda, Maryland 20892, and ${ }^{2}$ Department of Neuroscience, \\ Brown University, Providence, Rhode Island 02912
}

Four of the five major sensory systems (vision, olfaction, somatosensation, and audition) are thought to use different but partially overlapping sets of neurons to form unique representations of vast numbers of stimuli. The only exception is gustation, which is thought to represent only small numbers of basic taste categories. However, using new methods for delivering tastant chemicals and making electrophysiological recordings from the tractable gustatory system of the moth Manduca sexta, we found chemical-specific information is as follows: (1) initially encoded in the population of gustatory receptor neurons as broadly distributed spatiotemporal patterns of activity; (2) dramatically integrated and temporally transformed as it propagates to monosynaptically connected second-order neurons; and (3) observed in tastant-specific behavior. Our results are consistent with an emerging view of the gustatory system: rather than constructing basic taste categories, it uses a spatiotemporal population code to generate unique neural representations of individual tastant chemicals.

Key words: neural coding; taste

\section{Significance Statement}

Our results provide a new view of taste processing. Using a new, relatively simple model system and a new set of techniques to deliver taste stimuli and to examine gustatory receptor neurons and their immediate followers, we found no evidence for labeled line connectivity, or basic taste categories such as sweet, salty, bitter, and sour. Rather, individual tastant chemicals are represented as patterns of spiking activity distributed across populations of receptor neurons. These representations are transformed substantially as multiple types of receptor neurons converge upon follower neurons, leading to a combinatorial coding format that uniquely, rapidly, and efficiently represents individual taste chemicals. Finally, we found that the information content of these neurons can drive tastant-specific behavior.

\section{Introduction}

By detecting and creating neural representations of the chemicals animals contact, the gustatory system informs feeding and other critical behaviors. Gustatory coding by the nervous system is

\footnotetext{
Received Sept. 11, 2014; revised July 14, 2015; accepted July 29, 2015.

Author contributions: S.R. and M.S. designed research;S.R., C.C.R., and K.S. performed research; M.S. contributed unpublished reagents/analytic tools; S.R. analyzed data; S.R. and M.S. wrote the paper.

This work was supported by National Institute of Child Health and Human Development, National Institutes of Health Intramural Grant to M.S. Light microscopy was performed at the Microscopy and Imaging Core, National Institute of Child Health and Human Development, with the assistance of V. Schram. Scanning electron microscopy was performed at the Electron Microscopy Core Facility, National Heart, Lung, and Blood Institute, with the assistance of P.M. Zerfas and C.A. Brantner. We thank G. Dold and T. Talbot of the National Institute of Mental Health Instrumentation Core Facility for assistance with designing the tastant delivery system; J. McFarland for assistance with data analysis; and G. Barnea, L. Belluscio, D. Berson, C.-H. Lee, C. McBain, D. Rinberg, and the members of the Stopfer laboratory for helpful discussions.

The authors declare no competing financial interests.

Correspondence should be addressed to Dr. Mark Stopfer, National Institute of Child Health and Human Development, National Institutes of Health, Bethesda, MD 20892. E-mail: stopferm@mail.nih.gov.

DOI:10.1523/JNEUROSCI.3802-14.2015

Copyright $\odot 2015$ the authors $\quad 0270-6474 / 15 / 3512309-13 \$ 15.00 / 0$
}

thought to be relatively simple: every chemical ("tastant") is associated with one of a small number of basic tastes (Erickson, 1984), and the presence of a basic taste, rather than the specific tastant, is represented by the brain. In mammals as well as insects, five basic tastes are recognized: sweet, salty, sour, bitter, and umami (Yarmolinsky et al., 2009; Liman et al., 2014). The neural mechanism for representing basic tastes is unclear. One general proposal is that, in both mammals and insects, gustatory information is carried through separate channels, from the periphery to sites deep in the brain, by cells sensitive to a single basic taste ("labeled line" code) (Frank, 1973; Marella et al., 2006; Yarmolinsky et al., 2009; Chen et al., 2011). An alternate proposal is that basic tastes are represented by populations of cells, with each cell sensitive to multiple basic tastes ("across fiber pattern" code) (Pfaffmann, 1941; Dethier and Crnjar, 1982; Glendinning et al., 2002, 2006; Lemon and Katz, 2007; Roussin et al., 2012).

Testing these ideas requires determining, point-to-point, how tastes are initially represented within the population of receptor cells and how this representation is transformed as it moves to 
higher-order neurons. However, it has been technically challenging to deliver precisely timed tastants while recording cellular activity from directly connected cells at successive layers of the gustatory system, particularly near the periphery. This is partly because taste receptor cells in the vertebrate tongue and soft palate transmit their activity to both afferent neurons and other taste cells through complex pathways that may interact and that do not use synapses (Chaudhari and Roper, 2010). The gustatory system of insects is analogous to the mammalian system in many ways, but its simplicity enables the point-to-point analyses needed to test basic ideas about gustatory coding.

To test basic ideas about gustatory coding, we studied the gustatory system of the moth Manduca sexta, a large insect amenable to gustatory stimulation, intracellular and extracellular electrophysiological neural recordings, and behavioral tests. Manduca are generalist foragers who use their $\sim 8$-cm-long proboscis to discriminate chemically diverse tastants and to drink nectar that contains plant-specific sugars and secondary compounds (Baker and Baker, 1983; Goyret and Raguso, 2006). The proboscis of moths can contain hundreds of sensilla, specialized hair cells of which at least four morphologically identified types have been implicated in gustation (Faucheux, 2013; Xue and Hua, 2014) (see Fig. 1a). Each chemosensory sensilla contains 2-4 gustatory receptor neurons (GRNs) (Mitchell et al., 1999), each of which expresses multiple gustatory receptors collectively sensitive to a wide range of tastants (Hodgson et al., 1955; Dethier, 1963; Baker and Baker, 1983; Jørgensen et al., 2006, 2007). The number of gustatory receptors (GRs) in Manduca is unknown, but there are likely a few dozen: a related moth species, Bombyx mori, expresses at least 69 GRs (Zhang et al., 2011), and the fruit fly Drosophila melanogaster expresses at least 68 (Liman et al., 2014).

We designed a new stimulus and recording system that allowed us to fully characterize, with high temporal resolution, the timing of tastant delivery, and the dynamics of the tastant-elicited responses of GRNs and their monosynaptically connected second-order gustatory neurons (SONs), before, during, and after tastant delivery. Surprisingly, we were unable to find evidence consistent with a basic taste model of gustation. Instead, we found that the moth's gustatory system represents individual tastant chemicals as spatiotemporal patterns of activity distributed across the population of GRNs. Further, we found these representations are transformed substantially as multiple types of GRNs converge broadly upon follower neurons. Our results suggest that the gustatory system generates unique combinatorial representations of individual tastants, enabling tastant-specific behaviors.

\section{Materials and Methods}

Experimental animals. Behavioral and physiological experiments were performed on a total of 244 male and female moths ( $M$. sexta) 1-3 d after eclosion. Moths were reared from eggs (Carolina Biological) on an artificial diet (Bell and Joachim, 1976) at $26^{\circ} \mathrm{C}$ in $>70 \%$ humidity, under a long-day photoperiod. Moths were housed individually in plastic cups before the experiments, which were conducted during their light cycle. Moths with fully extended wings, intact proboscis and antennae, and an overall healthy appearance were used for experiments.

Tastant delivery system. The distal two-thirds of the moth's proboscis was threaded into a rigid tube and fixed in place with epoxy. A small piece of mesh was installed $5 \mathrm{~mm}$ above the proboscis. The coiled proboscis rested against this mesh, ensuring that, for each animal, the proboscis was placed in the same location. Throughout each experiment, filtered water was pumped continuously through the rigid tube and over the proboscis by a peristaltic pump (Manostat Compulab 3) at $40 \mathrm{ml} / \mathrm{min}$. The output of a pressurized 16-channel perfusion system (Bioscience Tools) was inserted into the rigid tube $1 \mathrm{~cm}$ above the mesh. For experiments with square pulses of tastant, compressed air from a PicoPump (World Precision Instruments, $10 \mathrm{psi}$ ) was directed for $1 \mathrm{~s}$ to the manifold of tastant solutions, and one of 16 valves was opened to allow a bolus of a given tastant containing a small amount of food coloring (Fast green FCF, Sigma, $0.05 \% \mathrm{w} / \mathrm{v}$ ) to enter the water flowing over the proboscis. Tastant concentration was monitored by a color sensor (FS-V31m, FY35-FZ reflective fiber unit, Keyence) installed $5 \mathrm{~mm}$ below the perfusion system output, adjacent to the proboscis. Color sensor signals, responding to the food coloring in the tastants, were amplified $5 \times$ by a DC amplifier (Brown-Lee model 440) and were recorded along with physiological data (see below), providing a precise record of the stimulus. Each stimulus pulse ended when the valve closed and the PicoPump was switched off; $0.05 \mathrm{w} / \mathrm{v}$ FCF produced color sensor signals $33.77 \mathrm{SD}$ above the noise level, calculated from the 4980 trials shown in Figure 2a. Control experiments in which tastants were delivered with and without FCF (data not shown) confirmed that the food coloring did not activate GRNs or alter their responses to tastants.

To estimate the concentration of tastant reaching the proboscis after entering the constant water stream, we performed a calibration experiment (data not shown). We first confirmed that tastant concentration is linearly related to the color sensor's signal by delivering various concentrations $(0-0.1 \mathrm{w} / \mathrm{v})$ of FCF and measuring the color sensor's response amplitude. We found our sensor provided linear output throughout the range of color intensity used in all experiments. We then tested whether tastants were diluted when injected into the constant water stream. We injected pulses of dyed tastant into a water stream containing the same concentration of dye as the tastant. We defined the color sensor's response to this as $100 \%$ concentration. Then, we measured the fraction of this color sensor signal with signals generated by injecting colored tastant into uncolored water. We estimated that, after dilution in the water stream, the concentration reaching the proboscis is $\sim 77 \%$ of the concentration of solutions listed throughout the text.

The tastant delivery system was controlled by a computer (Optiplex 780, Dell) running custom LabVIEW software (PCI-MIO-16E-4 DAQ cards, National Instruments). All trials of a given tastant were delivered in sequence as a block (5-8 trials), and blocks of tastants were delivered in random order. All tastant presentations were separated by 10 s. All 16 tastant tubes of the perfusion system converged into a single manifold, so the first trial of each block of tastant delivery consisted of a mixture of current and previous tastants. Because of this, the first trial with each tastant was excluded from analysis.

Tastant stimuli. Some tastants and concentrations were selected because of their known ecological importance to Manduca, who feed primarily on plant nectar that is rich in sucrose and also contains potentially toxic alkaloids (Baker and Baker, 1983; Adler, 2000; Hare and Walling, 2006). Other tastants and concentrations were selected because they are very widely used to represent the basic taste categories (Marella et al., 2006; Kvello et al., 2010; Weiss et al., 2011). All tastants were obtained from Sigma-Aldrich at the highest available purity and were dissolved in reverse osmosis filtered (Millipore) water before experiments. Pure water was also used as a control for mechanical or other stimulation. Tastant solution concentrations match those commonly used in the gustation literature. Unless a different concentration is given in the text, tastants used were as follows: sucrose, glucose, trehalose, maltose $(1000 \mathrm{~mm}$, "sweet" tastes); sodium chloride, lithium chloride, and potassium acetate (1000 mM, "salty" tastes); caffeine (100 mM), (-)-lobeline hydrochloride, berberine chloride, and denatonium benzoate $(10 \mathrm{~mm}$, "bitter" tastes; these concentrations of "bitter" tastants were delivered, as is routine in the gustation literature (Marella et al., 2006; Weiss et al., 2011) because these chemicals do not readily dissolve into water (higher concentrations are therefore unlikely to have physiological relevance). As noted above, all tastants were further diluted by the delivery water stream.

Physiological preparation. Intact moths $(N=73)$ were fitted into tubes with their heads exposed. After protecting the proboscis and antennae by placing them in small plastic tubes secured with epoxy, a wax cup was built up around the ventral side of the head capsule. The dorsal part of the 
head capsule was first opened, and the buccal compressor muscle (Davis and Hildebrand, 2006) was cut to ensure the brain's stability during recordings. This opening was then sealed with wax. The ventral side of the head capsule was then opened, and the wax cup was filled with Manduca physiological saline (Christensen and Hildebrand, 1987), bathing the brain. The labial palps, exoskeleton, and trachea covering the subesophageal zone (SEZ) (Ito et al., 2014) of the brain were removed. The saline was then removed and replaced with a solution of collagenase/ dispase (Roche Diagnostics) crystals dissolved in saline (10\% w/v). After this caused the dilator-3 muscles (Davis and Hildebrand, 2006) to tear (2-3 $\mathrm{min}$ ), the collagenase mixture was replaced with saline. The sheath covering the SEZ and the proximal maxillary nerve was then removed with fine forceps. For stability, a platform made from a flattened insect pin was inserted through the esophagus underneath the SEZ, and secured with wax to the tube containing the moth. During experiments, a constant flow of fresh saline was delivered to the exposed brain.

Electrophysiology. Borosilicate glass tubes (outer diameter $1.0 \mathrm{~mm}$, Sutter Instruments) were pulled into sharp electrodes for intracellular recordings by a horizontal puller (P87, Sutter Instruments) to a resistance of 80-120 M . Intracellular solution was $1 \mathrm{M} \mathrm{KAc}$ or $5 \%$ Neurobiotin (Vector Labs) dissolved in $1 \mathrm{M} \mathrm{KCl}$. To stabilize recordings from SONs, $-0.05 \mathrm{nA}$ current was injected throughout experiments. Some SONs were filled with neurobiotin by injecting $0.5-1 \mathrm{nA}$ positive current at $0.33 \mathrm{~Hz}$ for $5-10 \mathrm{~min}$.

Multichannel extracellular recordings were made using custom-built bundles of twisted-wire electrodes (tetrodes), preamplifier, and amplifier (Biology Electronics Shop, Caltech) (Perez-Orive et al., 2002). Such electrodes have proved highly effective for recording neural activity in Manduca (Ito et al., 2008, 2009). Probes were made with 3-8 electrode wires, with the best recordings obtained from probes with 4 wires; probes with fewer wires yielded fewer well-isolated units, and probes with more wires were difficult to fit into the small maxillary nerve. These tetrodes were inserted into the exclusively afferent (Davis and Hildebrand, 2006) maxillary nerve, allowing any recorded cells to be unambiguously classified as first-order afferent neurons. Tetrodes were positioned across the full depth and cross section of the nerve, allowing random sampling of these cells. Pilot intracellular recordings made from this location with sharp glass electrodes showed responses matching those obtained with tetrodes (data not shown). The maxillary nerve contains mechanosensory as well as gustatory afferent neurons. Because our tastant delivery system presented a constant mechanical input throughout the experiment, neurons responding specifically to tastant presentations could be distinguished from mechanosensory cells and could be identified unambiguously as GRNs. Data were collected at $40 \mathrm{kHz}$ (custom LabVIEW software), amplified 3000 times, and bandpass filtered $300 \mathrm{~Hz}$ to $6000 \mathrm{~Hz}$.

Histology. For dextran fills of the maxillary nerve, a patch pipette $(\sim 10$ $\mathrm{M} \Omega$ ) was backfilled with a $5 \%$ solution of dextran crystals (tetramethylrhodamine, $3000 \mathrm{MW}$, Invitrogen) dissolved in water, and the solution was pressure injected into the nerve after connecting the back of the pipette to a $10 \mathrm{cc}$ syringe. As described previously (Ito et al., 2009), brains with neurobiotin-filled neurons were conjugated with streptavidin AlexaFluor-488 or -568 (Invitrogen). Whole-mounted brains were imaged by a Zeiss 510 inverted confocal microscope. Some labeled SONs were immunostained for GABA using a published protocol (Perez-Orive et al., 2002). Briefly, after imaging, brains were rehydrated through an ethanol series and then washed in Triton X-100 (PBST). Brains were agitated in $10 \%$ goat serum overnight and then incubated for $5 \mathrm{~d}$ in a goat serum-PBST solution containing rabbit anti-GABA antibodies (Sigma) diluted 1:100. Brains were then washed for $4 \mathrm{~h}$ in PBST and then incubated in goat anti-rabbit IgG conjugated to AlexaFluor-633 or -568. After a final wash in PBS, brains were dehydrated, cleared, and imaged as above.

Image processing. $Z$ stacks of neurobiotin and dextran fills of GRNs/ SONs were examined using FluoRender software (University of Utah).

Scanning electron microscopy. Proboscises, which tend to curl tightly, were linearized by threading them into glass capillary tubes filled with fixative $(2.5 \%$ glutaraldehyde, $1 \% \mathrm{PFA}$, in $0.12 \mathrm{M}$ sodium cacodylate buffer, $\mathrm{pH}$ 7.38) and refrigerated overnight. The capillaries were then flushed 4 times with buffer, refixed for $2 \mathrm{~h}$ in $1 \%$ osmium in buffer, washed 4 times with water, stained en bloc with $1 \%$ uranyl acetate in water for $1 \mathrm{~h}$, washed 4 times in water, and dehydrated in an ethanol series. Two 15 min changes of hexamethyldisilazane (Sigma) were performed, with the last one evaporated off in a chemical fume hood. Proboscises were then cut into three segments (distal, middle, proximal), positioned on carbon adhesive tape with silver paint, coated with $10 \mathrm{~nm}$ gold in an EMS $575 \times$ sputter coater (Electron Microscopy Sciences), and imaged with a Hitachi S3400-N1 SEM (Hitachi High Technologies). Mosaic images shown in Figure $1 a$ were prepared in Photoshop (Adobe).

Identification of SONs. Pilot experiments, including both physiological recording and anatomical reconstruction, revealed that our blind sharp electrode recordings from the SEZ came from only two clearly different types of neurons (data not shown). One type extended an axon down through the cervical connective toward the body ganglia and showed unambiguous, stereotypical subthreshold membrane potential activity, spike shape, and baseline spike rate $(n=16$ recordings and fills in 16 moths). We were subsequently able to use these features to reliably identify these descending neurons from their physiological characteristics alone. The other type of neuron was the SON discussed in the main text ( $n=12$ recordings and fills in 12 moths). All recorded neurons not identified as descending neurons were analyzed as SONs.

Data analysis. All analyses were performed with scripts custom written in MATLAB (The MathWorks). Unless otherwise specified, statistics reported throughout the text are mean \pm SEM. Nonparametric statistical tests were used for results shown in Figure $6 b, c$ because these data did not pass Lilliefors test of normality ( $p<0.05)$.

Spike sorting. We used a semiautomated, model-based spike sorting method that has proved highly effective for tetrode recordings made from neurons in Manduca (Ito et al., 2008, 2009). This method compares the whole waveform of spike signals across multiple tetrode channels. After sorting extracellular spike waveforms as cited by Pouzat et al. (2002), quantitative estimates of cluster quality were made using the method of Hill et al. (Fee et al., 1996; Hill et al., 2011). To judge whether a cluster was well isolated and stable throughout an experiment, we considered whether the sorted waveforms had physiological shapes, whether they were well isolated in principal component space, and whether the estimated Type 1 and Type 2 errors (arising from spikes missed through signal thresholding, spikes misclassified because of overlap with other clusters, and the occurrence of nonphysiological interspike intervals) fell beneath $5 \%$ of the dataset. To prevent any bias in our selection of units, spike sorting and unit selection were performed before any analysis of the responses of GRNs to tastants. As noted above, pilot intracellular recordings made from the maxillary nerve with sharp glass electrodes showed responses matching those obtained with tetrodes following spike sorting.

Determining whether a neuron responds to a tastant. We examined recordings from neurons in an animal stimulated with a tastant by first estimating the firing rate of a neuron by smoothing trial-averaged spike times with a Gaussian filter ( $\mathrm{SD}=60 \mathrm{~ms}$ ). We defined background activity as the firing rate of the neuron in the first second of the trial, before the tastant was delivered. Because it is not always obvious when a neuron is responding to a stimulus, we considered a range of response thresholds (T). A neuron was considered to respond to a tastant if, following tastant delivery, its firing rate exceeded its mean background activity plus the product of $\mathrm{T}$ and the $\mathrm{SD}$ of the background activity, or fell below the mean background activity minus the product of $\mathrm{T}$ and the $\mathrm{SD}$ of the background activity. Figures show a range of responses thresholds; throughout the text, response statistics were calculated using a threshold of $\mathrm{T}=5$. Also, throughout the text, "response strength" was defined as the absolute value of the difference between the mean firing rate during the stimulus time and the background activity.

Tastant discrimination task. Twelve-way classification of tastant identity was performed using all the recordings from GRNs shown in Figure 2a. Seven-way classification of tastant identity using SONs or GRNs (see Fig. 7c) was performed using sucrose, trehalose, maltose, $\mathrm{NaCl}, \mathrm{KAc}$, caffeine, and lobeline, as shown in Figure $7 a$.

The spike rate of each neuron in the analysis was first estimated by smoothing the single trial spiking activity with a Gaussian filter (SD $=60$ $\mathrm{ms}$ ). In a few trials, classification performance exceeded chance at times before the tastant was delivered because of slow changes in spike rate that 
could "wrap around" from one trial to the next (e.g., some responses of GRN 70 and 72; see Fig. 2a). To remove this artifact, for classification analysis only, in each trial the mean of the first second of each trial (baseline activity) was subtracted from the trial. As desired, this manipulation lowered the baseline classification success to chance while leaving peak classification performance unaffected. The dimensionality of the dataset was then reduced using principal component analysis, with the number of components chosen to preserve $>90 \%$ of the dataset's variance. The resulting dimensionality was 19 for 12-way GRN classification and 8 for 7 -way SON classification.

We next performed a standard classification task, using variable lengths of GRN responses following tastant delivery to study how integrating tastant representations over time affects classification success. With leave-one-out cross validation, we averaged the population activity evoked by different trials of $N$ (either 12 or 7) tastant presentations to obtain $N$ cluster centroids. Classification was considered successful if the left out trial was closest, measured by Euclidean distance, to the centroid evoked by the tastant used to generate the test trial. This procedure was repeated for every trial of every tastant presentation. Results were averaged over trials, producing $N$ trial mean classification rates for the $N$ tastants. The plots in Figures $4 a$ and $7 c$ show the mean \pm SEM of these data.

Standard hierarchical clustering was performed using the Euclidean distance between the spiking responses of the GRN population $(n=83)$, smoothed as above, over entire trials (10 s). Distance between spiking responses was normalized by dividing by the average intertrial distance across all delivered tastants.

Determining whether neurons were monosynaptically connected. We used standard electrophysiological measures to determine whether particular GRNs and SONs were monosynaptically connected. We calculated the spike-triggered average (STA) between every pair of simultaneously recorded GRN (recorded extracellularly by tetrodes) and SON (recorded intracellularly). If a given GRN and SON are monosynaptically connected, spikes in the GRN will align precisely, after a very brief and consistent synaptic delay ( $<5 \mathrm{~ms}$ ), with well-shaped EPSPs in the SON (Jortner et al., 2007; Papadopoulou et al., 2011; Cassenaer and Laurent, 2012) (see Fig. 6a), as detailed below. Several factors could potentially mask the presence of an EPSP in the STA and thus had to be addressed. Because the presence of SON spikes immediately following a GRN spike would mask any EPSP waveform, we only considered GRN spikes that were not followed by an SON spike within $200 \mathrm{~ms}$. Tastant delivery sometimes induced strong fluctuations in the SON membrane potential that could potentially mask EPSPs. To minimize this confound, we excluded GRN spikes occurring during our square pulse tastant stimulation. Because this procedure prevents an assessment of synaptic connectivity between SONs and GRNs that were completely silent in the absence of tastant, to assess connectivity to these GRNs, we also opened our tastant valve without applying air pressure, providing a weak stimulus sufficient to sporadically activate otherwise silent GRNs, but not strong enough to induce strong membrane potential variability. STAs were judged to indicate monosynaptic connections if a physiologically plausible, and significant short-latency, EPSP waveform was seen following the time of GRN spikes. Significance was achieved when a waveform crossed 5 SDs from the background activity calculated from the average $100 \mathrm{~ms}$ before GRN spiking ( 8 of 70 pairs). The start of the EPSP waveform was estimated as the time-point where the STA crossed 3 SDs above the background. This was required to occur within $5 \mathrm{~ms}$ of the GRN spike (7 of 8 pairs). The mean latency of these pairs was $2.80 \pm 0.28 \mathrm{~ms}$, consistent with monosynaptic delay (Jortner et al., 2007; Papadopoulou et al., 2011). Tastants used for paired recordings were sucrose (100 and $1000 \mathrm{~mm}$ ), $\mathrm{NaCl}$ (100 and 1000 $\mathrm{mm})$, caffeine (10 and $100 \mathrm{~mm}$ ), and water, as in Figure $6 c$.

Behavioral assay. We measured the probability and duration of proboscis extension elicited by a variety of tastants: 50, 250, 500, 750, and $1000 \mathrm{~mm}$ sucrose; glucose; trehalose; maltose; $\mathrm{NaCl}$; and KAc; 5, 25, 50, 75 , and $100 \mathrm{~mm}$ caffeine; and 0.5, 2.5, 5, 7.5, and $10 \mathrm{~mm}(-)$-lobeline hydrochloride (see Tastant stimuli). A total of 171 1- to 2-d-old unfed moths were fixed vertically in tubes with the head exposed and the proximal third of the proboscis threaded into narrow tubing (Ito et al., 2008). The moths' eyes were painted over with ink to eliminate visual cues. Animals rested in position for $15-20 \mathrm{~min}$ before experiments began.
Each behavioral trial began with manual delivery of $50 \mu \mathrm{l}$ of a tastant solution (Sorenson $200 \mu$ l pipette) to the distal two-thirds of the proboscis. Five minutes later, the proboscis was washed with distilled water, and the next tastant stimulus was delivered. A single moth was used for 5 such behavioral trials, each separated by $5 \mathrm{~min}$. All trials were recorded by a digital video camera (Flea 3, Point Gray) for later analysis. Stimuli were presented in random order, with the experimenter blind to the stimulus throughout testing and scoring. There were no significant differences in the average extension rate between the first and last of 5 trials $\left(\chi^{2}\right.$ test, $\left.\chi^{2}(1, N=342)=0, p=1\right)$, indicating an absence of order effects. Epochs of proboscis extension were manually scored from video using a GUI custom written in MATLAB (The MathWorks). Proboscis extension was noted on trials when the moth raised it for $>1 \mathrm{~s}$ following delivery of the tastant. Extension probability is shown; very similar results were obtained when total proboscis extension duration was analyzed (Pearson's linear correlation coefficient for probability and duration measures $=$ $0.85, p=1.2 \mathrm{e}-12$ ). To examine the dependence of proboscis extension probability on the identity of the tastant, results for each tastant were pooled across concentrations, and the resulting proportions were compared ( $\chi^{2}$ tests; see Fig. 8 ).

\section{Results}

\section{Initial encoding of tastants}

In moths, signals generated by GRNs located in sensilla dotting the distal third of the proboscis provide information needed by the animal to discriminate tastants (Fig. 1a) (Dethier, 1963). GRNs project from the proboscis to a region of the brain called the SEZ (Ito et al., 2014) through the maxillary nerve (Davis and Hildebrand, 2006). To observe how the gustatory system initially represents tastants, we sought to characterize the responses of the GRN population, including the temporal patterns of spiking elicited by tastants. We thus designed new methods for delivering discrete and precisely timed pulses of tastants and for recording the responses of individual GRNs (Fig. 1b; see Materials and Methods). The moth's proboscis was sealed into a water stream, and pulses of tastant solution were injected into the stream, stimulating GRNs located in sensilla studding the distal two-thirds of the proboscis. Using bundles of extracellular electrodes (tetrodes; Fig. $1 b$ ) to record spiking activity from random locations in the purely afferent maxillary nerve (Fig. 1c), we could identify GRNs by their specific responses to tastants and unambiguously distinguish them from mechanosensory and other types of neurons. We used these methods to test the responses of 83 randomly selected GRNs to $1 \mathrm{~s}$ square pulses of each of 12 diverse tastants (Fig. $2 a$; 8 moths, 25 experiments). In biological terms, detection of a "response" depends on the sensitivity of downstream neurons to the spiking of GRNs; thus, we determined whether a neuron had responded to a tastant using a broad range of thresholds, from well below to well above generally accepted response values (Perez-Orive et al., 2002) (see Materials and Methods), to evaluate the robustness of our results.

Our recording method allowed us to characterize spiking in GRNs before, during, and after the stimulus was delivered. We found that GRNs displayed different levels of baseline activity before tastant delivery, ranging from silence (e.g., Fig. $2 a$; GRNs 1-28) to intense spiking (e.g., GRNs 67-69). GRNs responded to tastants with diverse sensitivities and activity patterns. Some cells responded to none of the tested tastants (e.g., Fig. 2a; GRN 77), indicating that they could be mechanosensory neurons, or GRNs sensitive to tastants not delivered. Some GRNs responded to only a single tastant (e.g., GRNs 1-27), whereas others responded to most tastants (i.e., GRNs 31 and 67; Fig. 2b). GRNs could respond with bursts of spikes to different sets of chemically diverse tastants (e.g., Fig. 2a; to sucrose and KAc: GRN 27; to sucrose, maltose, $\mathrm{NaCl}, \mathrm{LiCl}$, and caffeine: GRN 31; to trehalose, maltose, 


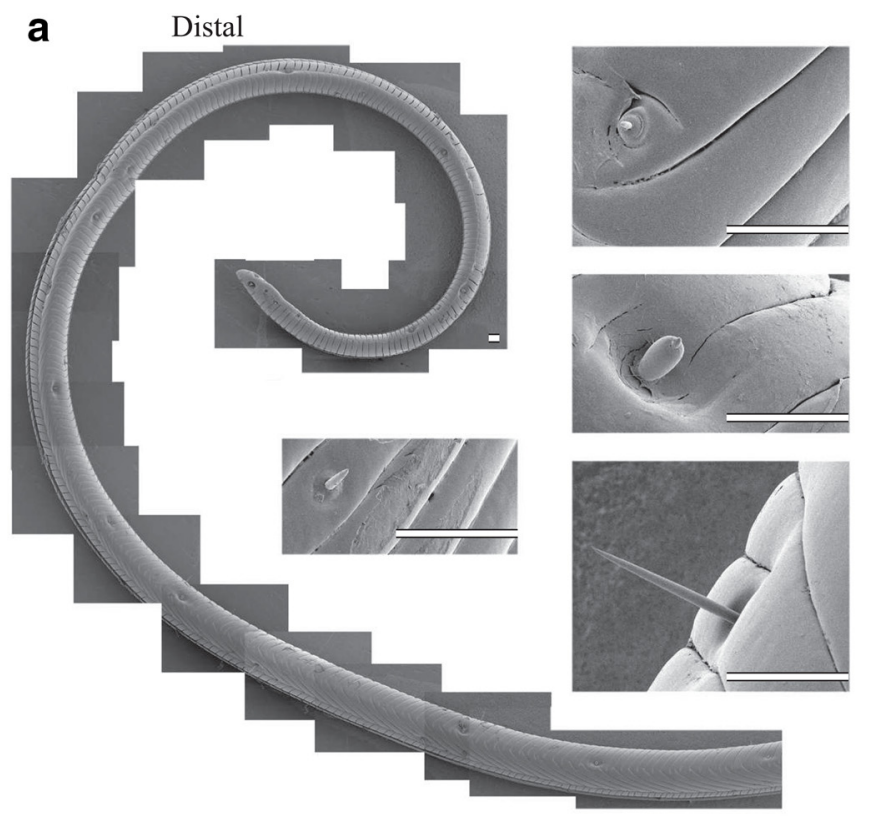

Middle
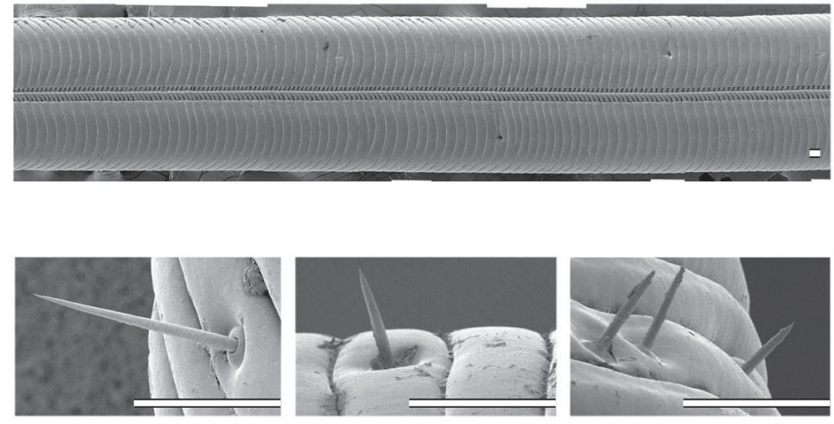

Proximal

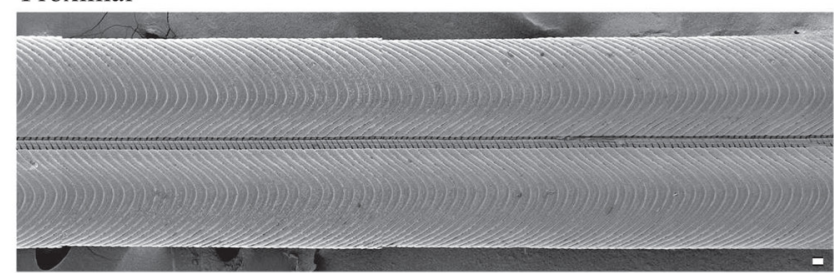

b

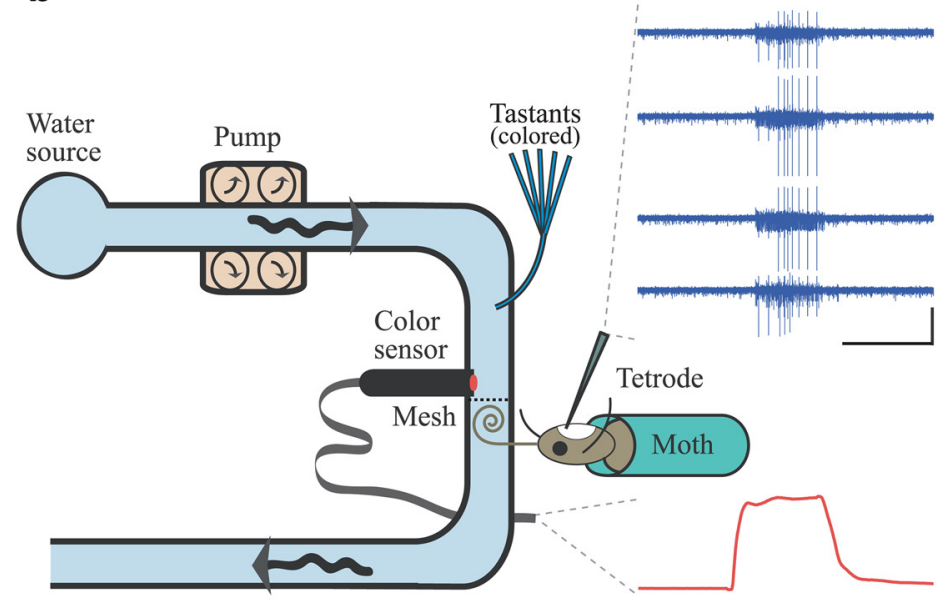

C

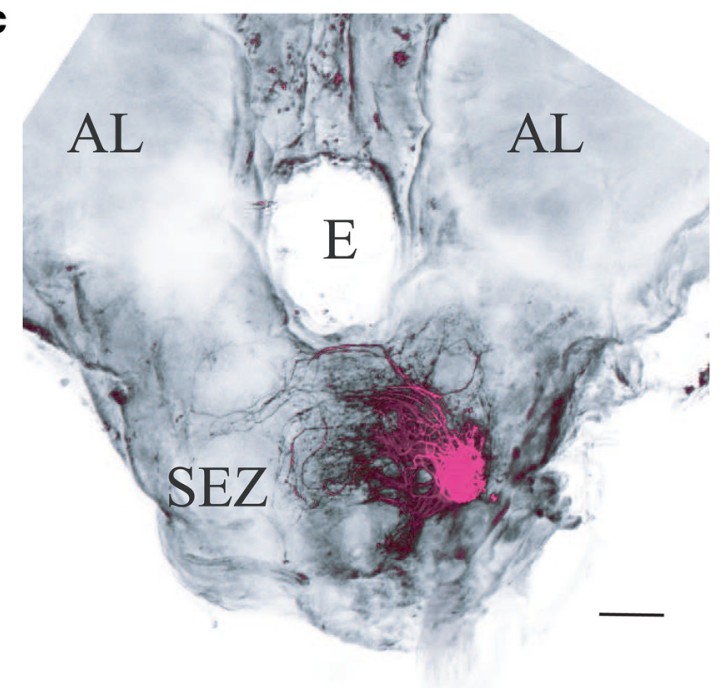

Figure 1. Monitoring the responses of GRNs to timed pulses of tastant. $\boldsymbol{a}$, Scanning electron micrographs of the proboscis. Left, Distal third (a portion of which is shown here) contains types of sensilla associated with chemoreception and mechanoreception. Insets (clockwise from top), Examples of sunken basiconic, styloconic, chaeticonic, and spire-shaped basiconic sensilla. Right, Middle and proximal portions of the proboscis contain primarily mechanoreceptive sensilla. Insets, Examples of chaeticonic sensilla (Faucheux, 2013). Scale bar, $50 \mu \mathrm{m}$. $\boldsymbol{b}$, A schematic of the apparatus. Dye-colored tastants were pressure injected into a water stream passing over the proboscis. The instantaneous concentration of tastant was monitored by a color sensor. Top inset, Example spiking responses from GRNs recorded by tetrode. Calibrations: vertical $=40 \times$ channel-wise median absolute deviation, horizontal $=1 \mathrm{~s}$. Bottom inset, Example color sensor trace showing tastant delivery (upward deflection, sucrose). Time axis as above.c, Frontal view of the moth brain. Magenta represents left maxillary nerve, filled with rhodamine-dextran. Scale bar, $100 \mu \mathrm{m}$. All recordings of GRNs were made from the exclusively afferent maxillary nerve which extends processes throughout the ipsilateral SEZ. AL, Antennal lobe; E, esophagus .

and $\mathrm{NaCl}$ : GRN 48), or with inhibition (e.g., to all tastants except caffeine: GRN 67 ). Notably, sucrose activated $\sim 60 \%$ of the GRNs (Fig. $2 c$ ), and $\sim 50 \%$ of the GRNs that responded to sucrose did not respond to any other delivered tastant (Fig. $2 d$ ). Other tastants each activated $\sim 30 \%$ of the GRNs, most of which responded to multiple tastants.

Our recording method also allowed us to characterize the timing of tastant-elicited responses with respect to the onset and offset of the stimulus. We found that a given GRN could respond with dramatically different spiking patterns to different tastants (Fig. 3a). For example, GRN 43 responded to $\mathrm{NaCl}, \mathrm{LiCl}$, and caffeine with different peak rates of spiking
(32, 68, and $22 \mathrm{~Hz}$ respectively), to KAc with spiking that outlasted the duration of tastant stimulation, and to lobeline and berberine with spiking ( 40 and $52 \mathrm{~Hz}$, respectively) that peaked only after the tastant was removed (Fig. $3 a$ ). Different GRNs could respond to the presentation of a single tastant with a wide diversity of spiking patterns (Fig. 3b). These patterns were reliable over repeated trials (see Fig. 2a).

The fact that different tastants activate different, but overlapping, subsets of the GRN population with tastant-specific temporal patterns of spiking activity demonstrates that information about the identity of specific tastants is contained within the GRN population as a spatiotemporal code. Assuming independent 
a

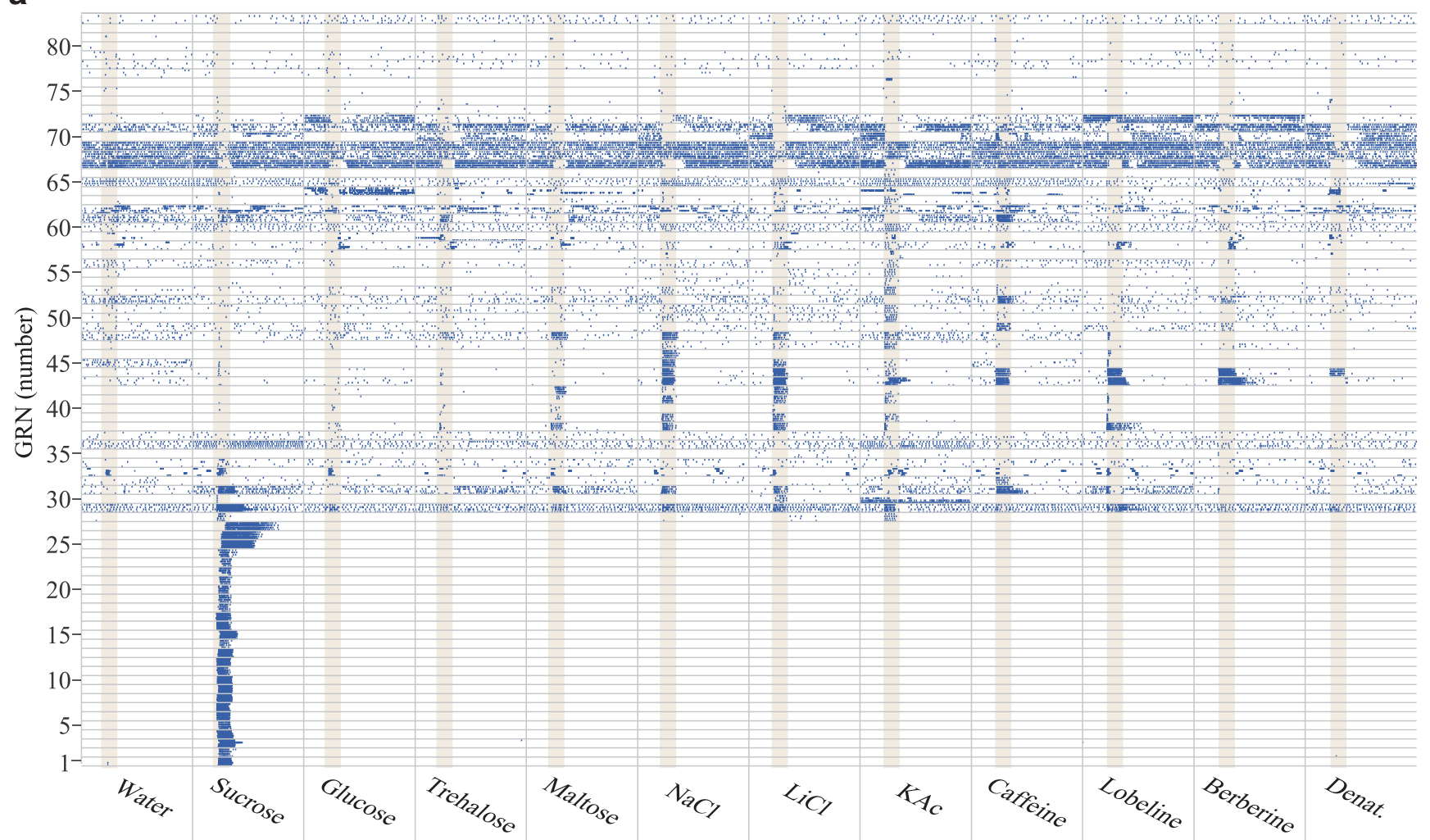

b

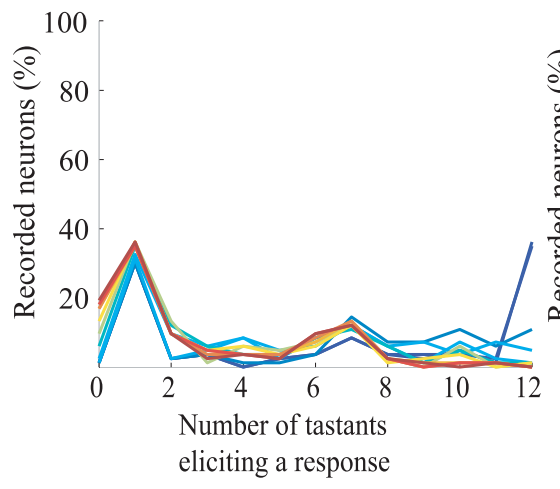

C

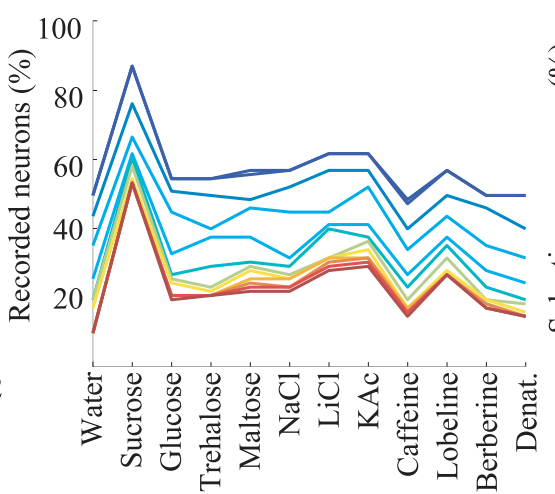

d

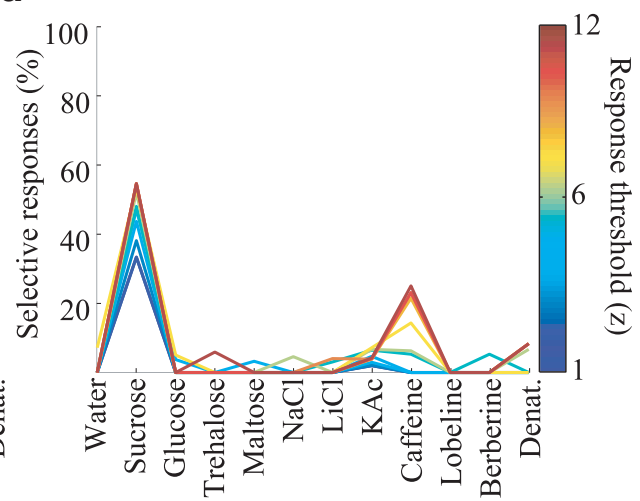

Figure 2. Tastant-elicited responses of GRNs are diverse and specific. $\boldsymbol{a}$, Raster plots represent responses of all 83 tested neurons (rows) to 12 tastants (columns, 4 trials/tastant shown, of 4 trials for water, 7 trials of all other tastants), ordered approximately by response characteristics. Yellow shading represents tastant presentation, $1 \mathrm{~s}$. For examples of spike sorting, see Figure $6 . \boldsymbol{b}-\boldsymbol{d}$, Summary of GRN responses shown in $\boldsymbol{a}$. All plots represent binary response classifications for a broad range of response-detection thresholds (1-12; see Materials and Methods). $\boldsymbol{b}$, Percentage of GRNs responding to different numbers of tastants. c, Percentage of GRNs responding to each tastant. $\boldsymbol{d}$, Percentage of GRNs responding exclusively to each tastant.

noise, we could estimate a lower bound of this encoded information by applying a standard classification analysis (12-way; see Materials and Methods) to our results. The identity of individual tastants could be determined significantly better than chance, with $62.50 \pm 9.97 \%$ accuracy $500 \mathrm{~ms}$ after tastant delivery, and with $75.0 \pm 9.73 \%$ accuracy $1 \mathrm{~s}$ after the delivery (Fig. $4 a$ ). The representations of different tastants were not equally separated in GRN population space: a standard hierarchical clustering analysis of the GRN tastant responses over time revealed that the response to sucrose was well separated, under a standard Euclidean distance metric, from the responses to all other delivered tastants (Fig. 4b). This is largely because sucrose activated many seemingly dedicated neurons (Fig. 2a). Notably, the responses of GRNs did not separate into basic taste categories: responses to tastants drawn from single basic taste categories were in general no closer to each other than they were to responses drawn from other basic taste categories.

Next, we tested the responses of GRNs to square pulses of different concentrations of tastants. Figure $5 a$ shows that most of the responses to sucrose varied with concentration in a simple and reliable way: increasing concentrations activated increasing numbers of GRNs to respond with increasing excitation or inhibition (Fig. $5 b$; 3 moths, 11 experiments, 20 GRNs; KruskalWallis test, $\chi^{2}(6, N=20)=51.52, p=2.3 \mathrm{e}-9$, post hoc Tukey's HSD, $p<0.05)$; other tastants elicited similar patterns of response (Fig. $5 c$; see Materials and Methods). The predictable, gradual manner in which GRNs responded to different concentrations of a tastant suggests that the GRN responses shown in 

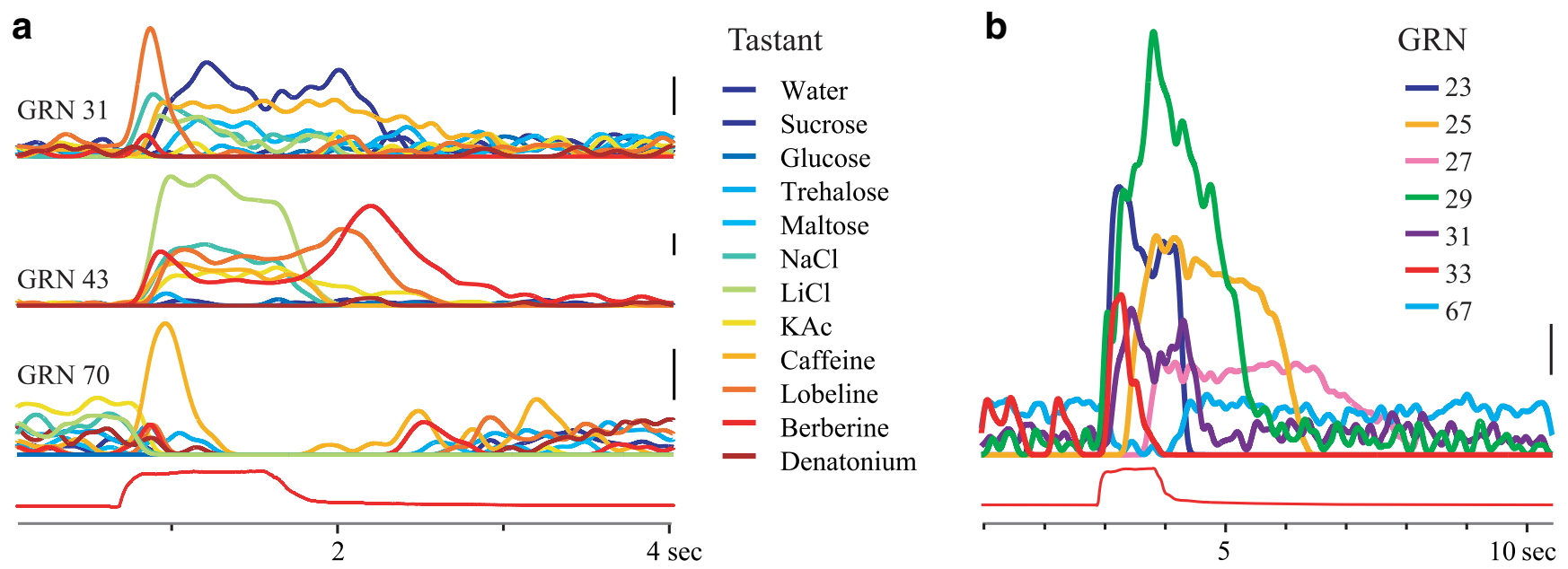

Figure 3. Temporal response properties of GRNs. $\boldsymbol{a}$, Histograms (trial-averaged spiking times smoothed with a Gaussian filter, SD $60 \mathrm{~ms}$ ). Timing of responses of GRNs varied with the tastant (color code at right). Bottom, red trace, Trial-averaged color sensor voltage indicates stimulus timing. $\boldsymbol{b}$, Histograms, Seven GRNs responded with different timing to the same stimulus (sucrose, 1000 mM). Scale bars, $10 \mathrm{~Hz}$. GRN numbers refer to Figure $2 a$.
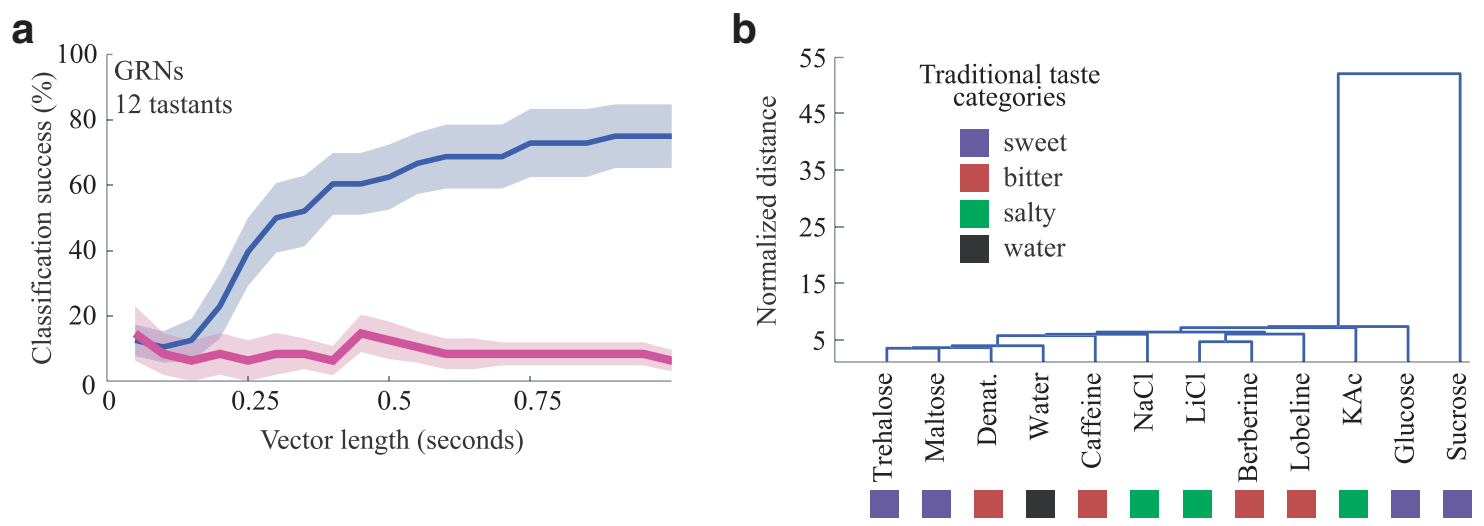

Figure 4. Quantifying information content of the spatiotemporal responses of GRNs. $\boldsymbol{a}$, Classification of tastant identity using the GRN population. Blue represents cross-validated success of 12-way classification of tastants using variable vector lengths of GRN responses ( $n=83$ neurons), beginning at the time of tastant delivery. Pink represents control, as blue, but including data taken before $(2 \mathrm{~s})$ tastant delivery. $\boldsymbol{b}$, Hierarchical clustering of the GRN population activity shows that their responses do not cluster by basic taste category. Distance was normalized to show the multiple of the average intertrial distance across tastants. Colored squares represent traditional basic taste categories from which different tastants were drawn ( $n=83$, see Materials and Methods).

Figure 2 do not merely reflect different sensitivities to the concentration of a tastant category but rather reflect selectivity to specific tastant identities.

\section{Transformation of tastant information}

How do follower cells respond to the information available in the activity of GRNs? We identified and recorded the activity of SONs using blind sharp electrode intracellular recordings in the anterior, ventral SEZ, to which axons of GRNs project (Fig. 1b) (Miyazaki and Ito, 2010). We also made intracellular recordings from these SONs simultaneously with extracellular recordings from GRNs. When spikes in a GRN were followed reliably in an SON by short latency ( $<5 \mathrm{~ms}$ ) EPSPs, the pair was considered to be synaptically connected (Jortner et al., 2007) (Fig. 6a; 18 moths, 36 experiments, 19 SONs, 70 GRNs, $N=70$ paired recordings; see Materials and Methods). Confocal reconstructions of a separate population of dye-filled SONs revealed cell bodies in the SEZ; most (15 of 18) clearly extended processes bilaterally into the region overlapping GRN projections in the anterior SEZ (Fig. $6 b)$. Often processes of SONs extended beyond this region into the more dorsal and posterior SEZ. Some dye-filled SONs showed positive immunostaining for the inhibitory neurotrans- mitter GABA, and some did not (data not shown; see Materials and Methods).

Notably, the paired simultaneous recordings showed that SONs nearly always responded to more tastants than their presynaptic GRNs (GRNs responded to $42.86 \%$ of the tastants, SONs to $77.55 \%$, correlation coefficient between response profiles $=0.17, N=7$ ). Even the most highly selective GRNs were found to synapse onto broadly responsive SONs (Fig. 6c). Comparing larger populations of neurons in nonpaired experiments, SONs responded to significantly more delivered tastants than did GRNs (Fig. $6 d, e ; \chi^{2}$ test, $\chi^{2}(1, N=83$ GRNs, 13 SONs from 10 moths $)=60.26, p=8.33 \mathrm{e}-15)$. Although sucrose activated a large subset of the GRNs (Fig. 2), sucrose did not activate significantly more SONs than any other tastant $\left(\chi^{2}\right.$ test, $\chi^{2}(1, N=13$ SONs $)=9.25, p=0.16)$. Indeed, SONs almost never responded exclusively to any delivered tastant (Fig. $6 f$ ). This suggests that multiple types of GRNs make synaptic connections with single SONs, that SONs interact laterally, or that both forms of convergence contribute to the SONs' broad responsiveness.

Square pulses of tastant elicited responses from SONs that often contained reliable sequences of excitation and inhibition that were generally more complex (Fig. 7a) than the relatively 

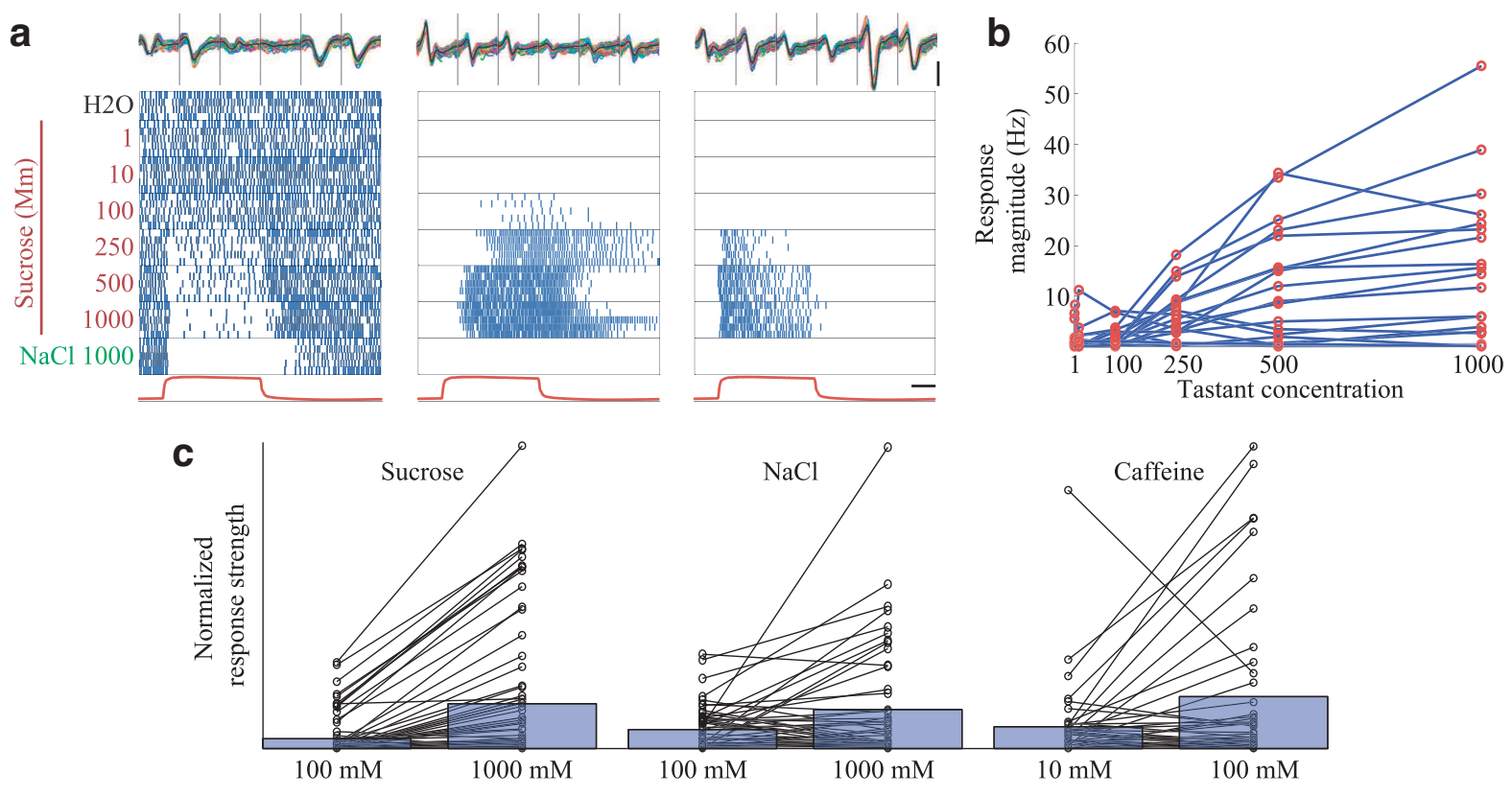

Figure 5. Increasing tastant concentration leads to stronger GRN responses. $\boldsymbol{a}$, Raster plots of three simultaneously recorded GRNs responding to pulses of water, 6 concentrations of sucrose, and $\mathrm{NaCl}$. Top, All extracellular recordings (6 wires) for each GRN together show the waveforms are well separated. Calibration: vertical $=20 \mathrm{SD}$ above noise level, horizontal $=1 \mathrm{~s}$. $\boldsymbol{b}$, Response magnitude of a population of GRNs increases with the concentrations of sucrose delivered in $\boldsymbol{a}$. Responses could be excitatory or inhibitory (see Materials and Methods). $\boldsymbol{c}$, Strength of GRN responses to two concentrations of sucrose: $\mathrm{NaCl}$, and caffeine. Black lines connect responses of single GRNs. Blue bars represent mean response strength across GRNs. For comparison, the response strengths are scaled so the strongest response for every pair of concentrations is equated. For all tastants, the higher concentration elicited stronger responses (1-tailed Wilcoxon signed rank tests; sucrose: $n=$ $75, z=5.77 p=3.86 \mathrm{e}-9 ; \mathrm{NaCl}: n=51, z=5.77, p=0.03$; caffeine: $n=44, z=1.77, p=0.04$.).
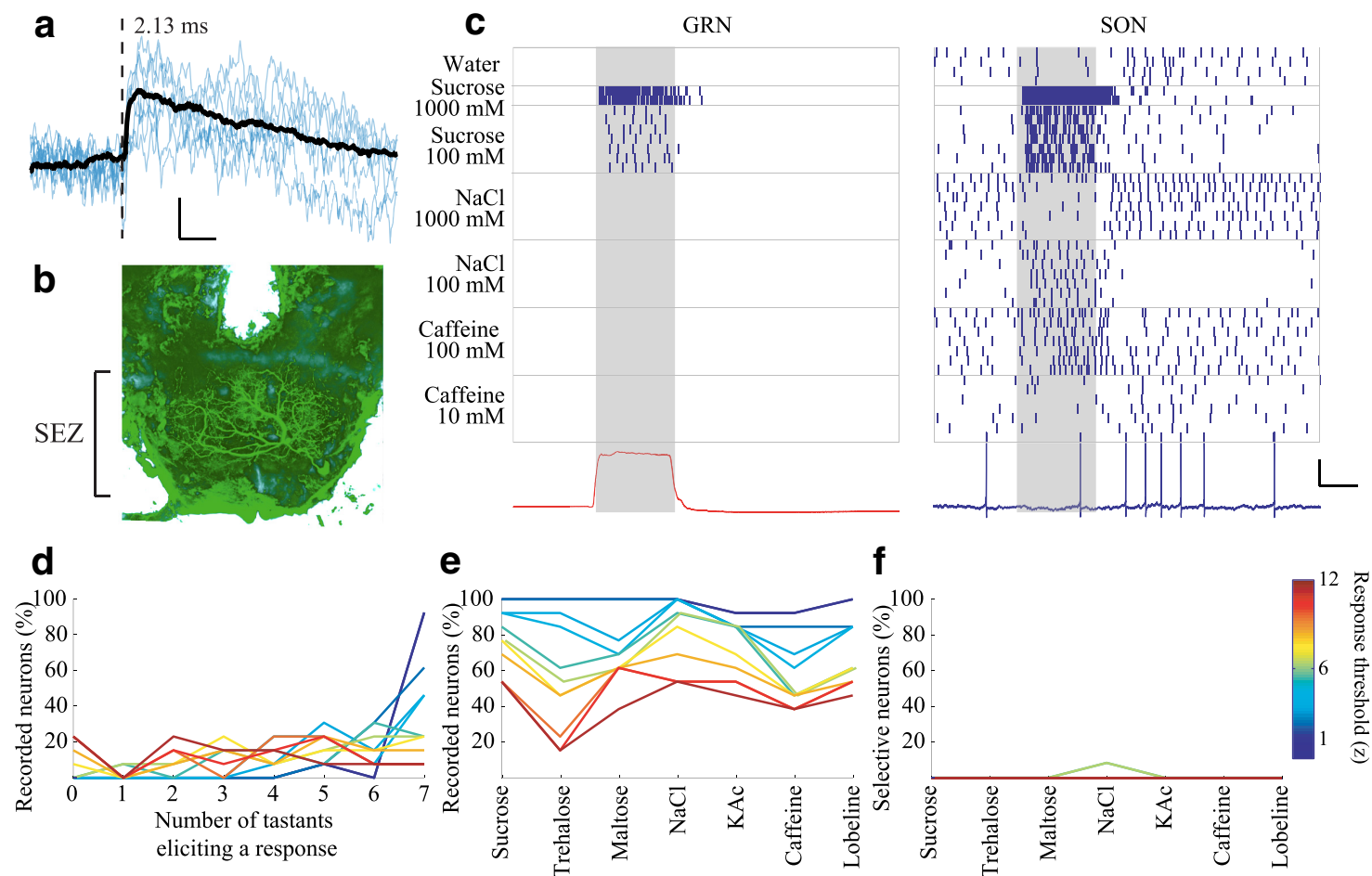

Figure 6. SONs transform the representations of tastants arising in GRNs. $\boldsymbol{a}$, Example STA EPSP provides physiological verification that a GRN-SON pair is monosynaptically connected. Calibration: vertical $=0.5 \mathrm{mV}$, horizontal $=25 \mathrm{~ms}$. Dashed line indicates GRN spike time ( $2.13 \mathrm{~ms}$ delay before EPSP onset). $\boldsymbol{b}$, Frontal view of the moth brain showing a single neurobiotin-filled SON in the anterior SEZ. c, Raster plots represent responses of an example simultaneously recorded, monosynaptically connected GRN and SON pair to different tastants. Bottom left, red trace, Average color sensor voltage. Gray shading represents tastant delivery. Bottom right, blue, Voltage record of the SON, last trial of the raster plot. The STA shown in $\boldsymbol{a}$ was generated from these two neurons. Calibration: vertical $=20 \mathrm{mV}$, horizontal $=1 \mathbf{s}$. $\boldsymbol{d}-\boldsymbol{f}$, Summary of SON responses $(n=13$, nonpaired recordings). $\boldsymbol{d}$, Percentage of SONs responding to different numbers of tastants. $\boldsymbol{e}$, Percentage of $\mathrm{SONs}$ responding to each tastant. $f$, Percentage of SONs responding exclusively to each tastant. 
a

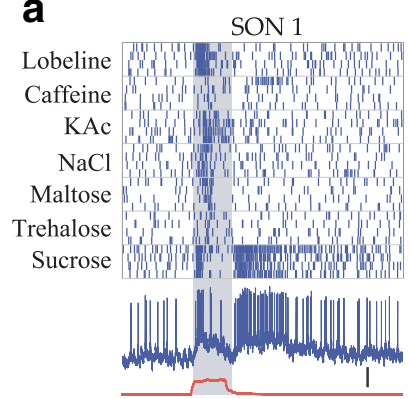

SON 5

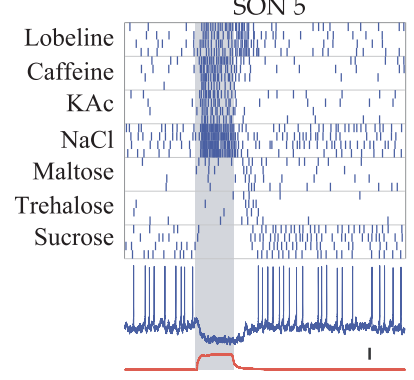

b

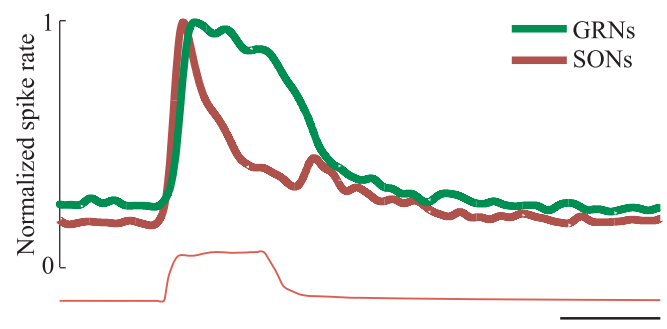

SON 2

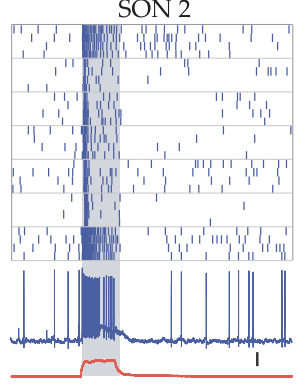

SON 6

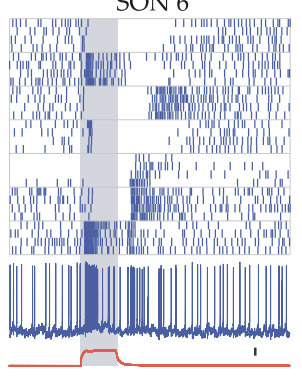

SON 3

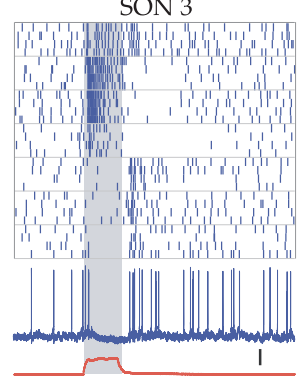

SON 7

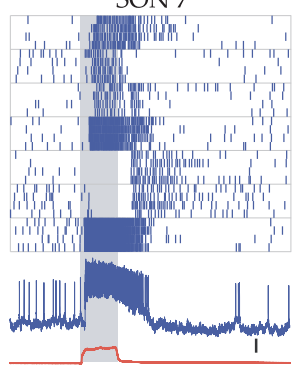

SON 4

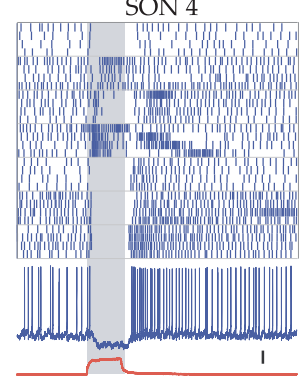

SON 8

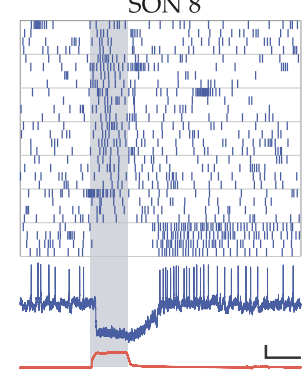

\section{C}

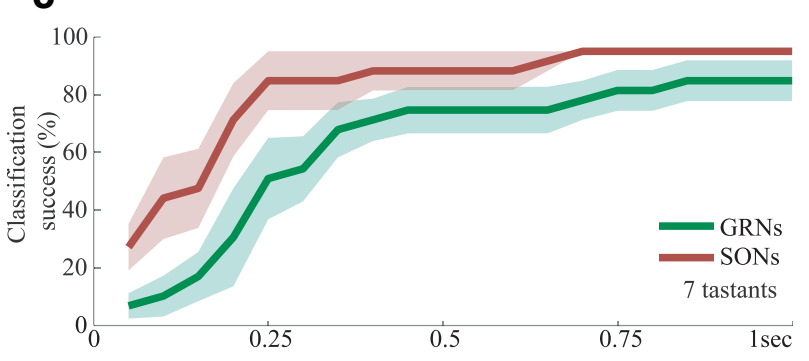

d

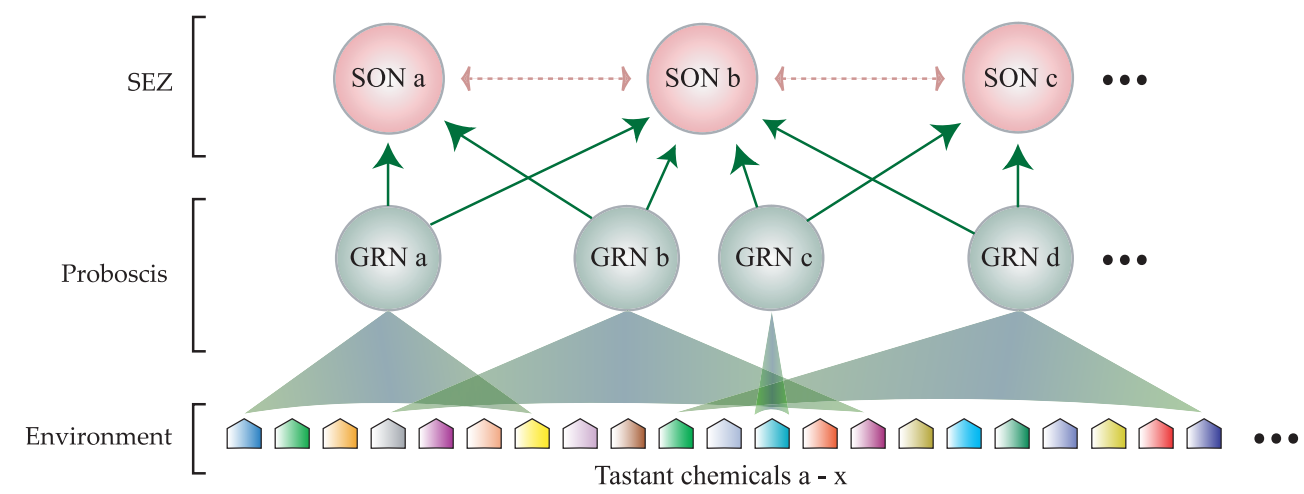

Figure 7. Spatiotemporal response properties of SONs. $a$, Raster plots of 8 example SONs responding with temporally structured firing patterns to various tastants. Blue and red traces and gray shading as in Figure $6 c$. Calibration: vertical $=10 \mathrm{mV}$, horizontal $=1 \mathrm{~s}$. $\boldsymbol{b}$, Histogram represents the average spiking response of GRNs (green, $n=83$ ) and SONs (red, $n=13$ ) elicited by $1 \mathrm{~s}$ delivery of the 7 tastants shown in $\boldsymbol{a}$. Spiking responses were smoothed with a Gaussian filter (SD $60 \mathrm{~ms}$ ) and normalized to show equal maximum average spike rates. Red trace represents average color sensor voltage. Calibration: 1 s. c, Given the same tastant set, SONs provided faster and more accurate tastant classification with fewer cells than GRNs. Comparison of 7-way classification using the GRN ( $n=83$, green) and SON responses ( $n=13$, red). Plots represent mean \pm SEM. $\boldsymbol{d}$, Schematic summary of our findings. Various tastant chemicals in the environment ( 24 examples are illustrated) are detected in the proboscis by GRNs that have overlapping sensitivities that range from narrow (GRN c) to broad (GRN d) (see Fig. 2a). Multiple GRNs converge upon each SON in the SEZ (see Fig. 6). We hypothesize that excitatory and inhibitory SONs (dotted arrows) may interact with each other, leading to elaborately structured firing patterns (a).

simple response patterns of most GRNs (Figs. 2a,3). The average of GRN responses followed the temporal profile of the stimulus. In contrast, the average of SON responses peaked at the onset and, to a lesser extent, the offset of the stimulus (Fig. 7b).

Given the responses of a population of SONs, our classification algorithm could identify the tastant with $92.86 \pm 7.14 \%$ accuracy $500 \mathrm{~ms}$, and $100 \pm 0 \%$ accuracy $1 \mathrm{~s}$, after tastant delivery (7 tastants, 13 neurons). Notably, given the same set of tastants, the responses of SONs could be used by the classification algorithm to discriminate tastant identity with greater accuracy, greater speed, and using fewer neurons, than the responses of GRNs (Fig. $7 c$ ). These results show that SONs integrate the activity of multiple types of GRNs in a way that allows for the unique and highly efficient representation of individual tastants through spatiotemporal patterns of spiking. Figure $7 d$ presents a model summarizing these findings. 


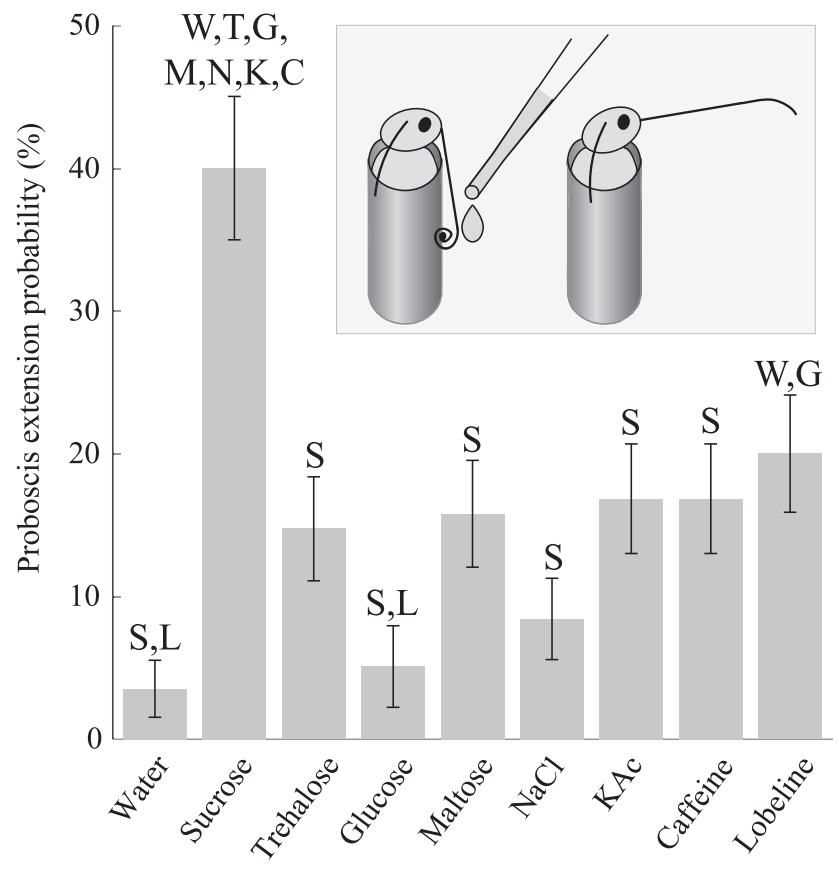

Figure 8. Proboscis extension is elicited by specific tastants. Probability of eliciting proboscis extension varied significantly for individual tastants ( $n=95$ moths/tastant). Error bars indicate SEM. Letters indicate initials of tastants eliciting significantly different response probabilities ( $p<0.05$, omnibus $\chi^{2}$ test followed by individual Bonferroni-corrected $\chi^{2}$ comparisons). Inset, Proboscis extension. Moths restrained in tubes were tested with metered drops of tastant onto the proboscis (see Materials and Methods).

\section{Tastant-specific gustatory behavior}

The presence of neural representations of individual tastants in the first two levels of the gustatory system suggests the animal could have access to information needed to generate behaviors appropriate not only for broad categories of tastants, but for specific tastants (Dethier, 1963). We examined the specificity of unconditioned proboscis extension behavior (Daly and Smith, 2000) elicited by contact with an assortment of tastants at concentrations commonly used in gustatory behavioral experiments to represent basic taste categories. A total of 171 moths were immobilized in small tubes, and tastant solution $(50 \mu \mathrm{l})$ was applied to the proboscis (see Materials and Methods). Sucrose elicited much more frequent proboscis extension than any other presented tastant, including trehalose, glucose, and maltose, sugars generally considered "sweet" (Fig. 8; omnibus $\chi^{2}$ test, $\chi^{2}$ (7, $N=855)=64.76, p=5.39 \mathrm{e}-11$, individual $\chi^{2}$ tests with Bonferroni correction, $p<0.05$, lobeline: $p=0.07$ ). Lobeline elicited significantly more extension than glucose or water $\left(\chi^{2}\right.$ tests with Bonferroni correction, $p<0.05$ ). Thus, consistent with the information we quantified in responses of GRNs and SONs, the animal's behavior revealed an ability to distinguish individual tastant chemicals.

\section{Discussion}

We developed a new, relatively simple model system and a set of techniques to investigate fundamental questions about how the nervous system represents tastes. Our approach allowed us to deliver and monitor tastants with high temporal precision while electrophysiologically recording the responses of large, random samples of GRNs and their SON followers. Our results showed that GRNs had a range of tuning specificity, from highly specific to very broad. Some GRNs responded to tastants drawn from multiple basic taste categories, and many GRNs did not respond to all tastants from any single category. We identified and characterized gustatory SONs and found that information about tastants is dramatically transformed across monosynaptically connected first- and second-order gustatory neurons. SONs were much more broadly tuned than GRNs, and, further, responded to tastants from more taste categories than those eliciting responses in their presynaptic GRNs.

Our methods for delivering timed, discrete tastant pulses and recording electrophysiological activity in a moth revealed that populations of both GRNs and SONs generated temporally structured patterns of spiking that contained information about individual tastants. These findings are consistent with a number of previous studies of Lepidoptera. Despite possessing only 16 GRNs, $M$. sexta caterpillars have been shown to behaviorally discriminate among aversive tastants that elicit different temporal patterns of spiking in partially overlapping sets of neurons (Glendinning et al., 2002, 2006). In addition, higher-order neurons in the moth Heliothis virescens, possibly analogous to the SONs we identified, respond to both appetitive and aversive stimuli (Kvello et al., 2010), a result consistent only with a population code. In the vertebrate, it has not yet been possible to analyze the temporal patterning of responses in taste receptor cells, but the timing of spikes has been shown to contain information about tastants in neurons at several subsequent stages along the gustatory pathway (Katz et al., 2001; Hallock and DiLorenzo, 2006; Lemon and Katz, 2007; Fontanini et al., 2009; Rosen et al., 2011; Wilson et al., 2012). Thus, our results from GRNs and SONs in Manduca, which fully characterize the temporally structured patterns of spiking as they are generated and transformed in the first two stages of processing gustatory information, are consistent with results obtained from other insects and vertebrates.

Historically, gustatory physiology has been understood in terms of basic tastes, originally perceptual categories (Erickson, 1984) that came to provide a framework for interpreting neural responses (Pfaffmann, 1959; Erickson, 2008). The strategy used by the gustatory system to represent basic tastes has long been debated; the two main proposals are that basic tastes are represented by successive populations of neurons dedicated to single basic tastes (labeled lines) (Yarmolinsky et al., 2009) or by populations of neurons responsive to multiple basic tastes (across fiber patterns) (Lemon and Katz, 2007). For example, in the vertebrate, temporally structured patterns of spiking across fibers have been proposed to carry information about basic taste categories (Hallock and DiLorenzo, 2006; Lemon and Katz, 2007).

Our results are difficult to reconcile with labeled line models of gustatory processing. If the gustatory system used labeled lines for basic tastes, GRNs should respond similarly to all the taste chemicals of a single basic taste category, and no chemicals of other categories. Further, and critically, they should synapse onto SONs that share their taste selectivity (Chandrashekar et al., 2006). Our results are inconsistent with these predictions. We found that both GRNs and SONs often responded very differently to different tastants from a single basic taste category, resulting in population responses that did not cluster by basic taste (Fig. $4 b$ ). Thus, our results also contradict across fiber pattern models of basic taste coding (Chandrashekar et al., 2006).

Our results instead suggest that the gustatory system generates representations of individual chemicals, not basic taste categories. Our quantitative analysis of information content 
shows that information sufficient to identify specific, individual tastant chemicals is contained in the activity of the GRN and SON populations. This analysis suggests chemical-specific information might be available to the animal for generating chemical-specific behavior. Indeed, consistent with this prediction, our behavioral tests showed the animal could discriminate among individual tastants drawn from a single basic taste category (for example, sucrose vs trehalose).

Behavioral tests alone cannot resolve how an animal distinguishes chemical stimuli; in principle, an apparent intensity difference evoked by two stimuli (for example, sucrose and caffeine), rather than their chemical identities, could be the distinguishing feature. However, the wide variety of neural response patterns evoked by changes in tastant identity in GRNs cannot be explained by the simple and predictable way these neurons respond to changes in tastant concentration. Thus, the results of our physiological and behavioral experiments and analysis suggest that the gustatory system encodes and provides information about the chemical identities of individual tastants.

To date, studies of gustatory coding in both insects and vertebrates have nearly always been interpreted in terms of basic tastes (Caicedo and Roper, 2001; Caicedo et al., 2002; Dahanukar et al., 2007; Lacaille et al., 2007; Cameron et al., 2010; Chen et al., 2011; Weiss et al., 2011; Wilson et al., 2012; Charlu et al., 2013; Jeong et al., 2013; Masek and Keene, 2013; Oka et al., 2013). In light of our new results, though, these earlier findings appear more consistent with a framework in which individual tastes are encoded. Molecular-genetic studies in Drosophila have revealed at least 68 types of gustatory receptors (Liman et al., 2014), far more than any proposed number of basic taste categories. Each GRN can express several different types of receptors, each sensitive to different tastant chemicals (Liman et al., 2014). In Drosophila, GRNs have been shown to respond to only some, but not all, tastants drawn from a basic taste category (Dahanukar et al., 2007; Weiss et al., 2011; Miyamoto et al., 2012), as well as to some, but not all, tastants from multiple categories (Wisotsky et al., 2011; Charlu et al., 2013; Jeong et al., 2013; Masek and Keene, 2013). Further, many GRNs respond to chemicals not readily associated with any of the basic tastes, such as fatty acids (Cartoni et al., 2010; Masek and Keene, 2013), carbon dioxide (Fischler et al., 2007), water (Cameron et al., 2010), and contact pheromones (Lacaille et al., 2007). In mammals, calcium imaging techniques have revealed that taste receptor cells are sensitive to specific, rather than whole categories of tastants (Caicedo and Roper, 2001; Caicedo et al., 2002). As with GRNs in Drosophila, mammalian taste receptor cells have also been shown to respond selectively to tastants drawn from multiple basic taste categories (Caicedo et al., 2002; Nelson et al., 2002; Oka et al., 2013), as well as to chemicals like carbon dioxide (Chandrashekar et al., 2009), fatty acids (Cartoni et al., 2010), and calcium (Tordoff et al., 2012), that, despite readily activating taste receptors, are difficult to place in any basic taste category. The basic taste framework has often needed ad hoc adjustments to accommodate new findings, including varying numbers of basic tastes (Ikeda, 2002; Sclafani, 2004) and exceptions for species-specific properties (Thistle et al., 2012).

Further, there exists no single clear definition of a basic taste. "Bitter," for example, is defined differently in different publications. Some define it by the behavior it elicits, equating "bitter" and aversive (e.g., Weiss et al., 2011). Others (e.g., Glendinning, 1994) associate "bitter" with specific chemicals (i.e., caffeine is by definition "bitter"). Others associate "bitter" with a given receptor (e.g., Lacaille et al., 2007) (i.e., the Drosophila pheromone Z-7-tricosene is "bitter" because it activates cells expressing the "bitter" receptor GR68a). These varying definitions can be ambiguous, mutually contradictory, and, perhaps most critically, can obscure the relationships between tastants and the neural and behavioral responses they evoke. By contrast, our proposal that the gustatory system encodes individual chemicals offers a clear, principled, and parsimonious interpretation of the growing collection of results, emerging from multiple levels of analysis and multiple species, that fit poorly into the basic taste framework. Given the extensive and multifaceted body of evidence presented here and in the literature, it seems likely that the gustatory system generates unique representations of individual tastes not only in Manduca, but in other insects and vertebrates, as well.

Tastants with similar chemical structures may sometimes, but certainly not always, evoke similar neural responses. In addition, distinct tastant representations, like those we observed near the sensory periphery in GRNs and SONs, may be grouped in different ways by subsequent neural processing stages. However, the ways such responses are grouped will most likely vary by species.

For example, our behavioral tests (Fig. 8) showed that Manduca could identify and show a strong preference for sucrose, consistent with observations that, in natural settings, Manduca prefer Datura wrightii, a flowering plant with sucrose-rich nectar (Riffell et al., 2008). Surprisingly, though, our results also showed that some Manduca opted to drink a solution containing lobeline, a canonical "bitter" tastant. The nectar of Datura, like that of many flowers (Adler, 2000), contains a number of "bitter" alkaloids (Hare and Walling, 2006); thus, Manduca may benefit from a species-specific tolerance, or even preference, for some "bitter" tastants. Indeed, the preferences of many species for different "bitter" tastants have been well documented (Glendinning, 1993). Together, these results suggest that taste preference is not described ideally by basic taste terminology, which emerged from early studies of how chemicals taste to people (Erickson, 1984).

In recent years, it has become widely accepted that other sensory modalities (olfaction, vision, audition, and somatosensation) use combinatorial neural codes to uniquely, rapidly, and efficiently represent sensory stimuli (Erickson, 2001). Our results suggest that gustation is no exception.

\section{References}

Adler LS (2000) The ecological significance of toxic nectar. Oikos 91:409420. CrossRef

Baker H, Baker I (1983) A brief historical review of the chemistry of floral nectar. New York: Columbia UP.

Bell RA, Joachim FA (1976) Techniques for rearing laboratory colonies of tobacco hornworms and pink bollworms lepidoptera-sphingidaegelechiidae. Ann Entomol Soc Am 69:365-373.

Caicedo A, Roper SD (2001) Taste receptor cells that discriminate between bitter stimuli. Science 291:1557-1560. CrossRef Medline

Caicedo A, Kim KN, Roper SD (2002) Individual mouse taste cells respond to multiple chemical stimuli. J Physiol 544:501-509. CrossRef Medline

Cameron P, Hiroi M, Ngai J, Scott K (2010) The molecular basis for water taste in Drosophila. Nature 465:91-95. CrossRef Medline

Cartoni C, Yasumatsu K, Ohkuri T, Shigemura N, Yoshida R, Godinot N, le Coutre J, Ninomiya Y, Damak S (2010) Taste preference for fatty acids is mediated by GPR40 and GPR120. J Neurosci 30:8376-8382. CrossRef Medline

Cassenaer S, Laurent G (2012) Conditional modulation of spike-timingdependent plasticity for olfactory learning. Nature 482:47-52. CrossRef Medline 
Chandrashekar J, Hoon MA, Ryba NJ, Zuker CS (2006) The receptors and cells for mammalian taste. Nature 444:288-294. CrossRef Medline

Chandrashekar J, Yarmolinsky D, von Buchholtz L, Oka Y, Sly W, Ryba NJ, Zuker CS (2009) The taste of carbonation. Science 326:443-445. CrossRef Medline

Charlu S, Wisotsky Z, Medina A, Dahanukar A (2013) Acid sensing by sweet and bitter taste neurons in Drosophila melanogaster. Nat Commun 4:2042. CrossRef Medline

Chaudhari N, Roper SD (2010) The cell biology of taste. J Cell Biol 190:285296. CrossRef Medline

Chen X, Gabitto M, Peng Y, Ryba NJ, Zuker CS (2011) A gustotopic map of taste qualities in the mammalian brain. Science 333:1262-1266. CrossRef Medline

Christensen T, Hildebrand J (1987) Male-specific, sex pheromone-selective projection neurons in the antennal lobes of the moth Manduca sexta. J Comp Physiol A Neuroethol Sens Neural Behav Physiol 160:553-569. CrossRef Medline

Dahanukar A, Lei YT, Kwon JY, Carlson JR (2007) Two Gr genes underlie sugar reception in Drosophila. Neuron 56:503-516. CrossRef Medline

Daly KC, Smith BH (2000) Associative olfactory learning in the moth Manduca sexta. J Exp Biol 203:2025-2038. Medline

Davis NT, Hildebrand JG (2006) Neuroanatomy of the sucking pump of the moth, Manduca sexta (Sphingidae, Lepidoptera). Arthropod Struct Dev 35:15-33. CrossRef Medline

Dethier VG (1963) The physiology of insect senses. New York: Wiley.

Dethier VG, Crnjar RM (1982) Candidate codes in the gustatory system of caterpillars. J Gen Physiol 79:549-569. Medline

Erickson RP (1984) Ohrwall, Henning and von Skramlik: the foundations of the four primary positions in taste. Neurosci Biobehav Rev 8:105-127. CrossRef Medline

Erickson RP (2001) The evolution and implications of population and modular neural coding ideas. Prog Brain Res 130:9-29. CrossRef Medline

Erickson RP (2008) A study of the science of taste: on the origins and influence of the core ideas. Behav Brain Sci 31:59-75; discussion 75-105. CrossRef Medline

Faucheux MJ (2013) Sensillum types on the proboscis of the Lepidoptera: a review. Ann Société Entomol Fr 49:73-90.

Fee MS, Mitra PP, Kleinfeld D (1996) Automatic sorting of multiple unit neuronal signals in the presence of anisotropic and non-Gaussian variability. J Neurosci Methods 69:175-188. CrossRef Medline

Fischler W, Kong P, Marella S, Scott K (2007) The detection of carbonation by the Drosophila gustatory system. Nature 448:1054-1057. CrossRef Medline

Fontanini A, Grossman SE, Figueroa JA, Katz DB (2009) Distinct subtypes of basolateral amygdala taste neurons reflect palatability and reward. J Neurosci Off J Soc Neurosci 29:2486-2495. CrossRef Medline

Frank M (1973) An analysis of hamster afferent taste nerve response functions. J Gen Physiol 61:588-618. CrossRef Medline

Glendinning JI (1993) Preference and aversion for deterrent chemicals in two species of Peromyscus mouse. Physiol Behav 54:141-150. CrossRef Medline

Glendinning JI (1994) Is the bitter rejection response always adaptive? Physiol Behav 56:1217-1227. CrossRef Medline

Glendinning JI, Davis A, Ramaswamy S (2002) Contribution of different taste cells and signaling pathways to the discrimination of "bitter" taste stimuli by an insect. J Neurosci 22:7281-7287. Medline

Glendinning JI, Davis A, Rai M (2006) Temporal coding mediates discrimination of "bitter" taste stimuli by an insect. J Neurosci 26:8900-8908. CrossRef Medline

Goyret J, Raguso RA (2006) The role of mechanosensory input in flower handling efficiency and learning by Manduca sexta. J Exp Biol 209:15851593. CrossRef Medline

Hallock RM, Di Lorenzo PM (2006) Temporal coding in the gustatory system. Neurosci Biobehav Rev 30:1145-1160. CrossRef Medline

Hare JD, Walling LL (2006) Constitutive and jasmonate-inducible traits of Datura wrightii. J Chem Ecol 32:29-47. CrossRef Medline

Hill DN, Mehta SB, Kleinfeld D (2011) Quality metrics to accompany spike sorting of extracellular signals. J Neurosci 31:8699-8705. CrossRef Medline

Hodgson ES, Lettvin JY, Roeder KD (1955) Physiology of a primary chemoreceptor unit. Science 122:417-418. CrossRef Medline
Ikeda K (2002) New seasonings. Chem Senses 27:847-849. CrossRef Medline

Ito I, Ong RC, Raman B, Stopfer M (2008) Sparse odor representation and olfactory learning. Nat Neurosci 11:1177-1184. CrossRef Medline

Ito I, Bazhenov M, Ong RC, Raman B, Stopfer M (2009) Frequency transitions in odor-evoked neural oscillations. Neuron 64:692-706. CrossRef Medline

Ito K, Shinomiya K, Ito M, Armstrong JD, Boyan G, Hartenstein V, Harzsch S, Heisenberg M, Homberg U, Jenett A, Keshishian H, Restifo LL, Rössler W, Simpson JH, Strausfeld NJ, Strauss R, Vosshall LB (2014) A systematic nomenclature for the insect brain. Neuron 81:755-765. CrossRef Medline

Jeong YT, Shim J, Oh SR, Yoon HI, Kim CH, Moon SJ, Montell C (2013) An odorant-binding protein required for suppression of sweet taste by bitter chemicals. Neuron 79:725-737. CrossRef Medline

Jørgensen K, Kvello P, Almaas TJ, Mustaparta H (2006) Two closely located areas in the suboesophageal ganglion and the tritocerebrum receive projections of gustatory receptor neurons located on the antennae and the proboscis in the moth Heliothis virescens. J Comp Neurol 496:121-134. CrossRef Medline

Jørgensen K, Stranden M, Sandoz JC, Menzel R, Mustaparta H (2007) Effects of two bitter substances on olfactory conditioning in the moth $\mathrm{He}$ liothis virescens. J Exp Biol 210:2563-2573. CrossRef Medline

Jortner RA, Farivar SS, Laurent G (2007) A simple connectivity scheme for sparse coding in an olfactory system. J Neurosci 27:1659-1669. CrossRef Medline

Katz DB, Simon SA, Nicolelis MA (2001) Dynamic and multimodal responses of gustatory cortical neurons in awake rats. J Neurosci 21:4478 4489. Medline

Kvello P, Jørgensen K, Mustaparta H (2010) Central gustatory neurons integrate taste quality information from four appendages in the moth $\mathrm{He}$ liothis virescens. J Neurophysiol 103:2965-2981. CrossRef Medline

Lacaille F, Hiroi M, Twele R, Inoshita T, Umemoto D, Manière G, MarionPoll F, Ozaki M, Francke W, Cobb M, Everaerts C, Tanimura T, Ferveur JF (2007) An inhibitory sex pheromone tastes bitter for Drosophila males. PLoS One 2:e661. CrossRef Medline

Lemon CH, Katz DB (2007) The neural processing of taste. BMC Neurosci 8:S5. CrossRef Medline

Liman ER, Zhang YV, Montell C (2014) Peripheral coding of taste. Neuron 81:984-1000. CrossRef Medline

Marella S, Fischler W, Kong P, Asgarian S, Rueckert E, Scott K (2006) Imaging taste responses in the fly brain reveal a functional map of taste category and behavior. Neuron 49:285-295. CrossRef Medline

Masek P, Keene AC (2013) Drosophila fatty acid taste signals through the PLC pathway in sugar-sensing neurons. PLoS Genet 9:e1003710. CrossRef Medline

Mitchell BK, Itagaki H, Rivet MP (1999) Peripheral and central structures involved in insect gustation. Microsc Res Tech 47:401-415. CrossRef Medline

Miyamoto T, Slone J, Song X, Amrein H (2012) A fructose receptor functions as a nutrient sensor in the Drosophila brain. Cell 151:1113-1125. CrossRef Medline

Miyazaki T, Ito K (2010) Neural architecture of the primary gustatory center of Drosophila melanogaster visualized with GAL4 and LexA enhancertrap systems. J Comp Neurol 518:4147-4181. CrossRef Medline

Nelson G, Chandrashekar J, Hoon MA, Feng L, Zhao G, Ryba NJ, Zuker CS (2002) An amino-acid taste receptor. Nature 416:199-202. CrossRef Medline

Oka Y, Butnaru M, von Buchholtz L, Ryba NJ, Zuker CS (2013) High salt recruits aversive taste pathways. Nature 494:472-475. CrossRef Medline

Papadopoulou M, Cassenaer S, Nowotny T, Laurent G (2011) Normalization for sparse encoding of odors by a wide-field interneuron. Science 332:721-725. CrossRef Medline

Perez-Orive J, Mazor O, Turner GC, Cassenaer S, Wilson RI, Laurent G (2002) Oscillations and sparsening of odor representations in the mushroom body. Science 297:359-365. CrossRef Medline

Pfaffmann C (1941) Gustatory afferent impulses. J Cell Comp Physiol 17: 243-258. CrossRef

Pfaffmann C (1959) The afferent code for sensory quality. Am Psychol 14: 226-232. CrossRef 
Pouzat C, Mazor O, Laurent G (2002) Using noise signature to optimize spike-sorting and to assess neuronal classification quality. J Neurosci Methods 122:43-57. CrossRef Medline

Riffell JA, Alarcón R, Abrell L, Davidowitz G, Bronstein JL, Hildebrand JG (2008) Behavioral consequences of innate preferences and olfactory learning in hawkmoth-flower interactions. Proc Natl Acad Sci U S A 105: 3404-3409. CrossRef Medline

Rosen AM, Victor JD, Di Lorenzo PM (2011) Temporal coding of taste in the parabrachial nucleus of the pons of the rat. J Neurophysiol 105:18891896. CrossRef Medline

Roussin AT, D'Agostino AE, Fooden AM, Victor JD, Di Lorenzo PM (2012) Taste coding in the nucleus of the solitary tract of the awake, freely licking rat. J Neurosci Off J Soc Neurosci 32:10494-10506. CrossRef Medline

Sclafani A (2004) The sixth taste? Appetite 43:1-3. CrossRef Medline

Thistle R, Cameron P, Ghorayshi A, Dennison L, Scott K (2012) Contact chemoreceptors mediate male-male repulsion and male-female attraction during Drosophila courtship. Cell 149:1140-1151. CrossRef Medline
Tordoff MG, Alarcón LK, Valmeki S, Jiang P (2012) T1R3: a human calcium taste receptor. Sci Rep 2:496. CrossRef Medline

Weiss LA, Dahanukar A, Kwon JY, Banerjee D, Carlson JR (2011) The molecular and cellular basis of bitter taste in Drosophila. Neuron 69:258-272. CrossRef Medline

Wilson DM, Boughter JD Jr, Lemon CH (2012) Bitter taste stimuli induce differential neural codes in mouse brain. PLoS One 7:e41597. CrossRef Medline

Wisotsky Z, Medina A, Freeman E, Dahanukar A (2011) Evolutionary differences in food preference rely on Gr64e, a receptor for glycerol. Nat Neurosci 14:1534-1541. CrossRef Medline

Xue S, Hua B (2014) Proboscis sensilla of the black cutworm Agrotis ypsilon (Rottemberg) (Lepidoptera: Noctuidae). J Asia Pacific Entomol 17:295301. CrossRef

Yarmolinsky DA, Zuker CS, Ryba NJ (2009) Common sense about taste: from mammals to insects. Cell 139:234-244. CrossRef Medline

Zhang HJ, Anderson AR, Trowell SC, Luo AR, Xiang ZH, Xia QY (2011) Topological and functional characterization of an insect gustatory receptor. PLoS One 6:e24111. CrossRef Medline 